\title{
PENILAIAN EROSI BERDASARKAN METODE USLE DAN ARAHAN KONSERVASI PADA DAS AIR DINGIN BAGIAN HULU KOTA PADANG-SUMATERA BARAT
}

\author{
Aprizon Putra, Triyatno, Azhari Syarief, Dedi Hermon \\ Jurusan Geografi, Fakultas Ilmu Sosial, Universitas Negeri Padang \\ Jln. Prof. Dr. Hamka Air Tawar, Padang, Sumatera Barat - 25131 \\ Email: aprizonputra@gmail.com
}

\begin{abstract}
Abstrak
Penelitian ini dilakukan untuk mengidentifikasi penggunaan lahan pada DAS Air Dingin bagian hulu di Kota Padang berdasarkan tingkat bahaya erosi dan arahan konservasi. Metode penelitian yang digunakan untuk mengetahui tingkat bahaya erosi ditentukan berdasarkan rumus Universal Soil Loss Equation (USLE) dan arahan konservasi mengacu pada modifikasi dari Kumajas (1992). Hasil penelitian menunjukan bahaya erosi sangat ringan yaitu 5.93 ton/ha/tahun dengan luas 58.61 ha, erosi ringan yaitu 43.9 ton/ha/tahun dengan luas 24.49 ha, erosi sedang yaitu 181.64 ton/ha/tahun dengan luas $3.91 \mathrm{ha}$, dan erosi berat yaitu 74.91 ton/ha/tahun dengan luas $4.33 \mathrm{ha}$. Sedangkan arahan konservasi pada erosi sangat ringan dibiarkan dalam keadaan alami, erosi ringan dilakukan dengan pembuatan teras bangku, erosi sedang dilakukan dengan rotasi tanaman dengan teras berdasarkan lebar (pemanfaatan mulsa), dan erosi berat dilakukan dengan teras bangku (penggarapan dengan tenaga manusia).
\end{abstract}

Kata Kunci: Erosi, Konservasi, DAS, Air Dingin bagian hulu, Kota Padang

\begin{abstract}
This research was conducted to identify the land use on the upstream part of Air Dingin Watershed in Koto Tangah Sub-district, Padang City based on the level of erosion and conservation directives. The method used to determine the level of erosion is determined based on Universal Soil Loss Equation (USLE) formula and conservation directives refers to the modification by Kumajas(1992). The results showed very mild erosion is 5.93 tons/ha/year with an area of $58.61 \mathrm{ha}$, mild erosion is 43.9 tons/ha/year with an area of 24.49 ha, moderate erosion is 181.64 tons/ha/year with an area of 3.91 ha, and heavy erosion is 74.91 tons/ha/year with broad 4.33 ha. While conservation directives on very mild erosion were left in a natural state, mild erosion is performed with a bench terracing, moderate erosion is being done by crop rotation with a terrace based on a width (mulsa utilization), and heavy erosion is done with a bench porch (cultivating with human labour).
\end{abstract}

Keywords: Erosion, Conservation, Watershed, Upstream Part of Air Dingin, Padang City

\section{PENDAHULUAN}

Bentangan lahan akan selalu mengalami proses erosi, disuatu tempat akan terjadi pengikisan sementara di tempat lain akan terjadi penimbunan, sehingga bentuknya akan berubah sepanjang masa. Peristiwa ini terjadi secara alami dan berlangsung sangat lambat, akibat yang ditimbulkan baru muncul setelah berpuluh bahkan beratus tahun kemudian (Nearing et al, 2017). Abidin et al (2017) menjelaskan proses pengikisan kulit bumi pada lahan yang terjadi secara alamiah disebut erosi atau dikenal juga sebagai erosi geologi. Erosi geologi merupakan erosi yang berjalan 
sangat lambat, dimana jumlah tanah yang tererosi sama dengan jumlah tanah yang terbentuk dan tidak berbahaya karena terjadi dalam keseimbangan alami tanpa ada campur tangan manusia.

Faktor-faktor yang mempengaruhi erosi meliputi hujan, angin, limpasan permukaan, jenis tanah, kemiringan lereng, penutup lahan, dan tindakan konservasi. Faktor-faktor tersebut mempengaruhi erosi yang sebetulnya tidak dapat dipisahkan satu dengan yang lainnya, artinya bekerja secara simultan (Morgan \& Rickson, 2005). Lebih lanjut (Julien, 2010) menjelaskan semua faktorfaktor tersebut dapat digolongkan ke dalam tiga kelompok yaitu 1) energi merupakan kemampuan potensial hujan, limpasan permukaan atau angin untuk menyebabkan erosi, kemampuan tersebut yaitu erosivitas; 2) Kepekaan tanah yang bergantung kepada sifat fisik dan kimia tanah, kemampuan tersebut yaitu erodibilitas; dan 3) proteksi yaitu bertitik tolak kepada faktor-faktor yang berhubungan dengan penutup lahan.

Penelitian kehilangan tanah yang disebabkan oleh erosi telah banyak dipublikasikan dengan menggunakan rumus Universal Soil Loss Equation (USLE), persamaan umum yang dikembangkan oleh Wischmeier \& Smith (1978) untuk menghitung besar erosi (Nouwakpo et al, 2016). Beberapa faktor yang mempengaruhi erosi dalam persamaan USLE yaitu faktor penggunaan lahan yang mempunyai pengaruh yang cukup besar terhadap bahaya erosi dengan tindakan konservasi yang diterapkan yaitu dengan penerapan sistem pertanian multiguna.

$$
\text { Dalam buku Young (1990) }
$$

dijelaskan bahwa salah satu bentuk pertanian multiguna adalah agroforestri atau wanatani yaitu pemanfaatan lahan yang meliputi penggabungan yang dapat diterima secara sosial dan ekologis antara pepohonan dengan tanaman pertanian secara berurutan. Prinsip utama dari agroforestri adalah penggabungan dua jenis tanaman yaitu tanaman semusim dan tanaman tahunan dalam satu lahan.

Berdasarkan penelitian Bhan \&

Behera (2014), penggunaan tanaman tahunan akan mempercepat terbentuknya bahan organik, memelihara kesuburan tanah, mengurangi erosi dan dapat menciptakan iklim mikro yang lebih baik sehingga dapat memberikan hasil yang dapat memelihara lingkungan dan peningkatan produksi lahan. Thomas et al, (2016) menjelaskan bahwa sistem penanaman campuran antara tanaman semusim dan tanaman tahunan dapat mengurangi erosi yang berlebihan sehingga degradasi lahan dapat dicegah.

Daerah Aliran Sungai (DAS) Air Dingin bagian hulu terletak di Kecamatan Koto Tangah, Kota Padang. Dilihat dari jenis penggunaan lahan yang paling mendominasi pada DAS Air Dingin bagian hulu yaitu hutan dan kebun campuran. Sebagian areal pada lahan kebun campuran tersebut memiliki kemiringan lereng yang curam. Dimana hal ini dapat memberikan pengaruh kemungkinan terjadinya erosi pada penggunaan lahan yang tidak sesuai dengan kemiringan lereng tersebut.

Bagian hulu DAS Air Dingin merupakan lokasi rawan erosi dan longsor. Bagian hulu DAS Air Dingin telah mengalami banyak perubahan akibat pemanfaatan lahan yang kurang sesuai dengan fungsinya yang disebabkan peningkatan jumlah penduduk. Berdasarkan data Badan Pusat Statistik (BPS) Kota Padang tahun 2016, Jumlah penduduk di Kecamatan Koto Tangah berjumlah 182.296 jiwa pada tahun 2015, sedangkan pada tahun 2010 jumlah penduduknya 162.079 jiwa (BPS, 2013).

Dengan dikeluarkannya Peraturan Pemerintah (PP) No. 26 Tahun 2011, pusat Pemerintahan Kota Padang secara resmi dipindahkan dari Kecamatan Padang Barat ke Kecamatan Koto Tangah. Dimana pemindahan tersebut bertujuan untuk mengurangi konsentrasi penduduk di kawasan pantai dan mendekatkan 
pelayanan kepada masyarakat serta mempercepat pertumbuhan ekonomi dan pembangunan di Kota Padang (Rusnam, 2013). Dalam situasi yang seperti ini nantinya bagian hulu DAS Air Dingin kemungkinan mengakibatkan terjadinya pembukaan/perluasan lahan baru seperti permukiman, konversi hutan menjadi lahan perkebunan dan infrastruktur yang nantinya akan mendukung kegiatan perluasan kota. Oleh sebab itu, diperlukan metode analisis tingkat bahaya erosi untuk mengetahui besarnya laju erosi yang terjadi dan arahan konservasi pada bagian hulu DAS Air Dingin.

\section{METODE PENELITIAN}

Secara astronomis bagian hulu DAS Air Dingin terletak pada koordinat $100^{\circ} 23^{\prime} 35^{\prime \prime}-100^{\circ} 30^{\prime} 36^{\prime \prime}$ BT dan $0^{\circ} 43^{\prime} 31^{\prime \prime}$ $0^{\circ} 50^{\prime} 45^{\prime \prime}$ LS. Lokasi penelitian merupakan DAS yang terletak di sebelah utara Kota Padang dengan batas wilayah yaitu di utara dengan DAS Kandis Kota Padang, Selatan dengan DAS Kuranji Kota Padang, Timur dengan DAS Air Dingin bagian tengah Kota Padang, dan Barat dengan Kabupaten Solok (Gambar 1).
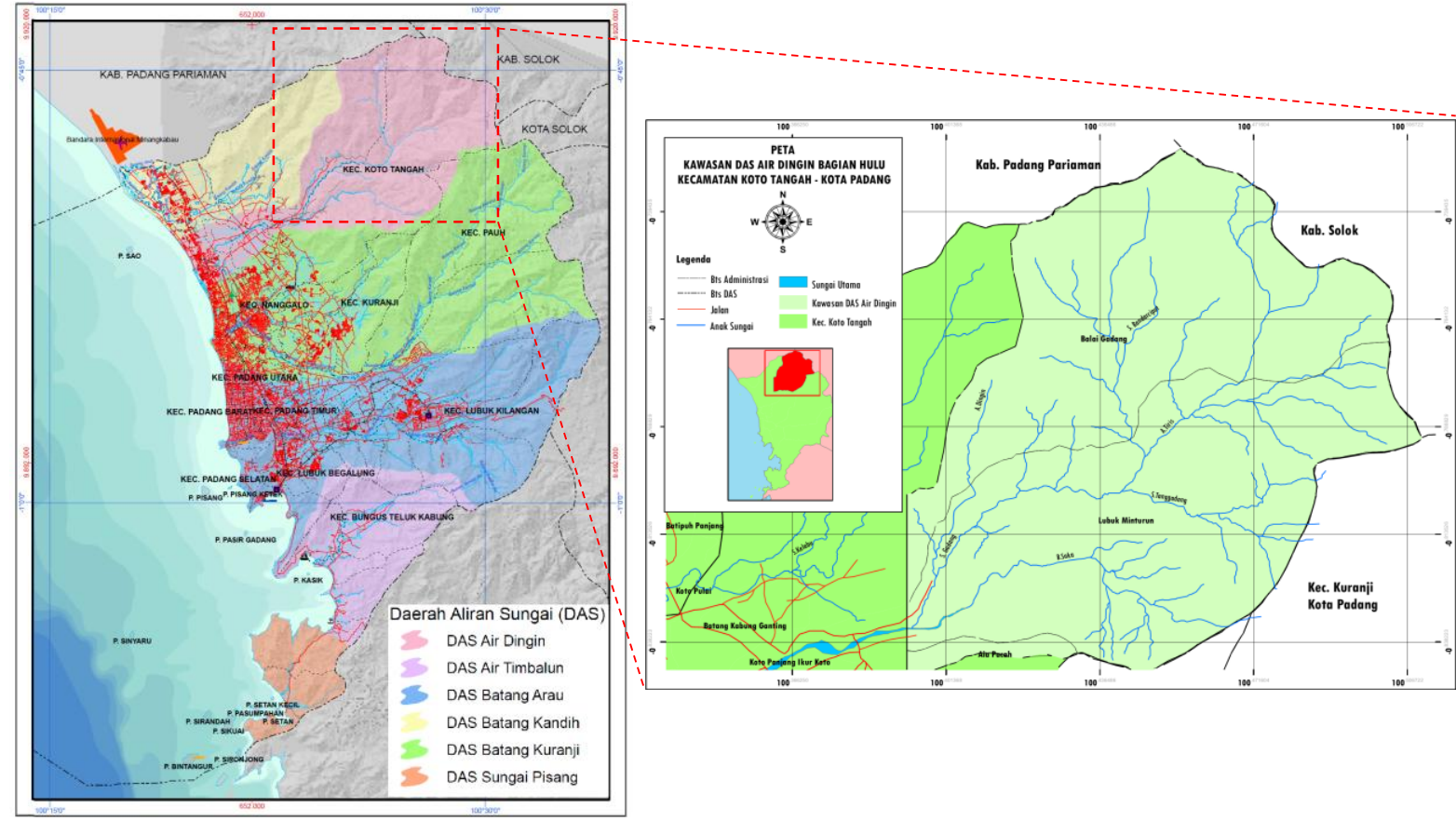

Gambar 1. Peta Pembagian DAS di Kota Padang dan DAS Air Dingin Bagian Hul.

Metode yang digunakan dalam penelitian ini adalah metode USLE yang dikembangkan oleh Wischmeier \& Smith (1978) (Ganasri \&Ramesh, 2016) untuk tingkat bahaya erosi dalam jangka waktu panjang dalam suatu kawasan dengan pendekatan Sistem Informasi Geografis (SIG), yaitu metode untuk memprediksi tingkat bahaya erosi secara spasial yang diperoleh dari hasil overlay data feature dalam format shapefile (SHP) untuk jenis tanah, kemiringan lereng, geologi, geomorfologi dan penggunaan lahan dalam bentuk database satuan lahan untuk indentifikasi sampel lokasi penelitian (Tabel 1 dan Gambar 2).

Tabel 1. Sampel Satuan Lahan Penelitian

\begin{tabular}{ccc}
\hline Satuan Lahan & Luas (ha) & $\mathbf{( \% )}$ \\
\hline V2.IV.QTau.And.Ht & 485 & $5 \%$ \\
V2.IV.QTau.Lat.Ht & 5376 & $59 \%$ \\
V2.III.QTt.Lat.Ht & 2392 & $26 \%$ \\
V2.III.QTau.Lat.Sbl & 433 & $5 \%$
\end{tabular}




\begin{tabular}{ccc}
\hline Satuan Lahan & Luas (ha) & $\mathbf{( \% )}$ \\
\hline V2.II.QTau.Lat.Kc & 391 & $4 \%$ \\
V1.II.Qal.Lat.Sw & 57 & $1 \%$ \\
\hline Jumlah & 9134 & $100 \%$ \\
\hline
\end{tabular}

Sumber: Data satuan lahan (2016) berdasarkan overlay data feature tanah, lereng, geologi, geomorfologi dan penggunaan lahan
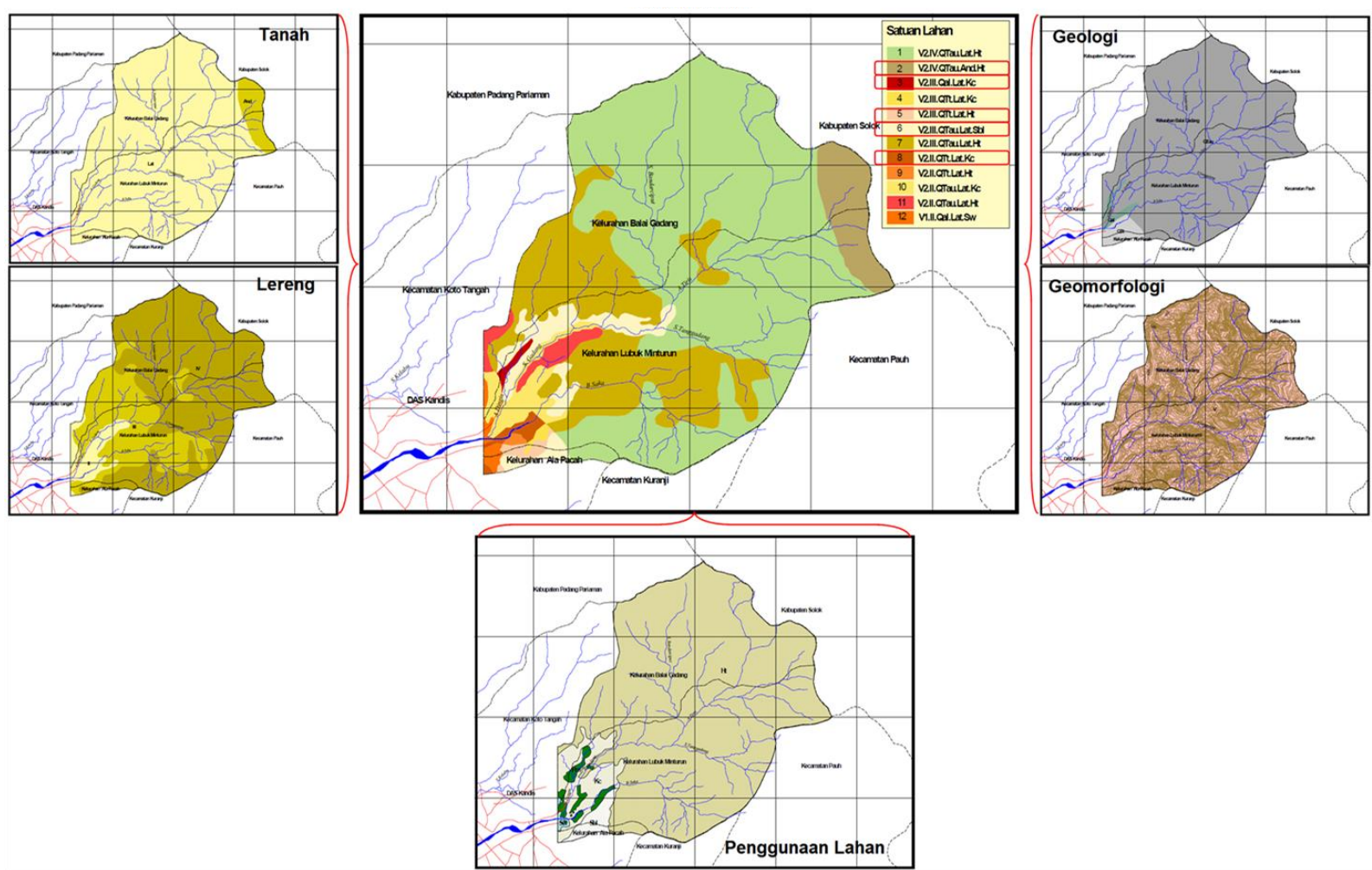

Gambar 2. Peta Satuan Lahan Berdasarkan Overlay Data Feature Tanah, Lereng, Geologi,

Geomorfologi dan Penggunaan Lahan

Proses pengolahan dan analisis data dilakukan pada data feature satuan lahan untuk memperoleh nilai-nilai parameter yang diperlukan dalam penghitungan tingkat bahaya erosi. Dari hasil overlay tersebut digunakan analisis dengan interaksi antara modifikasi metode USLE dari penelitian Sharma (2008) dan analisis SIG untuk memprediksi tingkat erosi serta luasannya secara spasial pada tiap satuan lahan dengan menggunakan rumus:

$$
\mathrm{A}=0.224 \text { (R. K. LS. C. P) }
$$

Keterangan:

$\mathrm{A}=$ Kehilangan tanah

$\mathrm{R}=$ Erosivitas

$\mathrm{K}=$ Erodibilitas

LS =Panjang $/$ kemiringan lereng
$\mathrm{C}=$ Penutup lahan

$\mathrm{P}=$ Arahan konservasi

Sedangkan kriteria yang digunakan untuk mendapatkan nilai tingkat bahaya erosi adalah dengan menggunakan klasifikasi berdasarkan solum tanah (Tabel 2) (Ruslan et al, 2016). Nilai kehilangan tanah didapat dari 0.224(R.K.LS.C.P) dibandingkan dengan solum tanah $(\mathrm{cm})$. 
Tabel 2. Klasifikasi tingkat bahaya erosi.

\begin{tabular}{cccccc}
\hline \multirow{2}{*}{ Solum (cm) } & I & II & III & IV & V \\
& $\mathbf{5 1 5}$ & $\mathbf{1 5 - 6 0}$ & $\mathbf{6 0 - 1 8 0}$ & $\mathbf{1 8 - 4 8 0}$ & $\mathbf{2 4 8 0}$ \\
\hline$\geq 90$ & SR(0) & R(I) & S(II) & B(III) & SB(IV) \\
$60-90$ & R(I) & S(II) & B(III) & SB(IV) & SB(IV) \\
$30-60$ & R(II) & B(III) & SB(IV) & SB(IV) & SB(IV) \\
$\leq 30$ & B(III) & SB(IV) & SB(IV) & SB(IV) & SB(IV) \\
\hline
\end{tabular}

(Sumber: KEMENHUT, 2009)

Keterangan: (SR -0) Sangat Ringan, (R-I) Ringan, (S-II) Sedang, (B -III) Berat, dan (SB-IV) Sangat Berat.

Untuk menentukan pengelolaan lahan dan tanaman agar besarnya erosi dapat ditekan menjadi sama atau lebih kecil dari erosi terbolehkan, maka dilakukan dengan mengganti besarnya tanah yang hilang dalam persamaan prediksi erosi (A) dengan maksimum kehilangan tanah yang ditoleransikan $(\mathrm{T})$ (Hastuti, 2004) yang menurut Arsyad (1989) untuk tanah di Indonesia sebesar 30 to/ha/th, sehingga dapat ditulis dalam bentuk persamaan sebagai berikut:

$$
\text { A } \leq \text { TR. K. LS. C. P } \leq \text { TC. P } \leq \frac{T}{R} \text {. K. LS }
$$

Keterangan:

$\mathrm{T}=$ Tanah yang ditoleransikan .

Nilai dari (R.K.LS) bertujuan menjaga agar tanah yang hilang oleh erosi tetap berada pada laju yang ditoleransikan. Maka, arahan konservasi diterapkan sedemikian rupa agar nilai $\mathrm{CP}$ tidak melebihi rasio T/R.K.LS. Pemilihan arahan konservasi mengacu pada modifikasi Kumajas (1992) pada Tabel 3 berikut.

Tabel 3. Arahan Konservasi

\begin{tabular}{|c|c|c|}
\hline \multicolumn{2}{|c|}{ Karakteristik lahan } & \multirow{2}{*}{ Arahan Konservasi } \\
\hline Lereng (\%) & Erosi & \\
\hline $0-3$ & Sangat ringan & $\begin{array}{l}\text { Pemupukan/pengapuran, penggunaan tanaman penutup dan } \\
\text { pupuk hijau penggunaan tanaman dan pupuk kandang serta } \\
\text { penggiliran tanaman }\end{array}$ \\
\hline $3-8$ & Ringan & $\begin{array}{l}\text { Pengelolaan menurut garis kontur, pemupukan, penggiliran } \\
\text { tanaman, pemakaian mulsa, da teras berdasar lebar }\end{array}$ \\
\hline $8-15$ & Sedang & Rotasi tanaman, pemanfaatan mulsa, teras berdasarkan lebar \\
\hline $15-30$ & Agak berat & $\begin{array}{l}\text { Teras bangku dengan penguat rumput, tanaman penutup tanah } \\
\text { rumput, penggiliran tanaman, pemanfaatan mulsa, pemberian } \\
\text { pupuk organik/anorganik, }\end{array}$ \\
\hline$x$ & $X$ & Teras bangku, penggarapan dengan tenaga manusia \\
\hline $30-45$ & Berat & Teras bangku, penggarapan denga tenaga manusia \\
\hline $45-65$ & Sangat berat & Tanaman penutup tanah permanen \\
\hline$>65$ & X & Di biarkan dalam keadaan alami \\
\hline
\end{tabular}

Sumber: Modifikasi Kumajas (1992)

\section{HASIL DAN PEMBAHASAN}

Erosivitas (R)

Faktor iklim yang paling mempengaruhi erosi adalah curah hujan. Curah hujan merupakan faktor iklim yang sangat berpengaruh terhadap terjadinya erosi. Besarnya curah hujan, intensitas, dan distribusi hujan menentukan kekuatan dispersi hujan terhadap tanah, jumlah dan kekuatan aliran permukaan 
serta tingkat kerusakan akibat erosi yang terjadi. Dalam penelitian Putra $d k k$, (2015); Rahmad dkk, (2017) dalam menentukan nilai erosivitas diperlukan data curah hujan selama 30 tahun terakhir (19862016) dan kemudian dihitung dengan rumus Bols (Bols, 1978; Luliro et al, 2013).

$$
\mathrm{EI}_{30} 2,34 . \mathrm{R}^{1,98}
$$

Keterangan:

$\mathrm{R}=\mathrm{CH}$ bulanan (1986-2016)(4222 mm/bl $=422,2 \mathrm{~cm} / \mathrm{bl})=2,34.422,2^{1,98}=2,34.835,96=$ $1956,15 \mathrm{~mm} / \mathrm{bl}$.

Dari hasil perhitungan tersebut diperoleh nilai erosivitas dalam setahun sebesar 1.956,15 mm/bl. Bila dikaitkan dengan kondisi topografi pada lokasi penelitian yang memiliki kemiringan lereng yang curam, maka dapat memungkinkan potensi terjadinya erosi oleh air hujan dengan jumlah yang besar.

Berdasarkan penelitian Hermon (2012), erosi akan meningkat dengan bertambahnya panjang lereng pada intensitas curah hujan tinggi, tetapi erosi akan menurun dengan bertambahnya panjang lereng pada intensitas hujan yang rendah. Dengan kondisi tersebut apabila tanah tidak ditutupi penutup tanah maka akan semakin meningkat aliran permukaan dan erosi.
Erodibilitas (K)

Berdasarkan hasil analisis laboratorium dari Balai Pengkajian Teknologi Pertanian (BPTP) Sumatera Barat untuk menentukan nilai erodibilitas menggunakan Metode clay ratio (Wang et al, 2013), terdapat 2 jenis tanah pada lokasi penelitian. Selanjutnya berdasarkan analisis SIG diketahui jenis tanah Andosol dengan luas 8.650 ha, kemudian jenis tanah Latosol dengan luas 484 ha (Tabel 4). Jenis tanah yang memiliki nilai erodibilitas tanah terbesar terdapat pada jenis tanah Andosol dengan nilai $\mathrm{K}$ sebesar 0,94 termasuk kriteria agak tinggi.

Berdasarkan penelitian Morgan \& Rickson (2005) semakin tinggi erodibilitas, maka semakin besar pula kemampuan tanah mengalami erosi. Arsyad (2010) menambahkan tanah yang mempengaruhi nilai erosi adalah erodibilitas dan berbagai tipe tanah mempunyai kepekaan terhadap erosi yang berbeda-beda. Apabila tanah memiliki kemampuan dalam menahan curah hujan, maka akan sedikit kemungkinan terjadinya erosi, begitu juga sebaliknya. Tanah yang erodibilitas tinggi akan peka terhadap erosi dibandingkan dengan tanah yang erodibilitas rendah memiliki daya tahan kuat terhadap erosi.

Tabel 4. Nilai Erodibilitas

\begin{tabular}{clccc}
\hline Satuan Lahan & Jenis Tanah & $\mathbf{( K )}$ & Luas(ha) & (\%) \\
\hline V2.IV.QTau.And.Ht & Andosol & 0,94 & 8650 & 95 \\
V2.IV.QTau.Lat.Ht & Latosol & 0,26 & 484 & 5 \\
V2.III.QTt.Lat.Ht & Latosol & 0,35 & - & - \\
V2.III.QTau.Lat.Sbl & Latosol & 0,94 & - & - \\
V2.II.QTau.Lat.Kc & Latosol & 0,32 & - & - \\
V1.II.Qal.Lat.Sw & Latosol & 0,91 & - & - \\
\hline & Total Luasan & & 9134 & 100 \\
\hline
\end{tabular}

Sumber: Hasil Analisis Laboratorium BPTP Sumatera Barat

Panjang dan Kemiringan lereng (LS)

Panjang dan kemiringan lereng merupakan unsur topografi yang menentukan kehilangan volume tanah apabila terjadi erosi. Berdasarkan analisis data kemiringan lereng menggunakan data Digital Elevation Model (DEM)
(Gambar 3), menunjukkan terdapat 3 kelas lereng pada lokasi penelitian. Hasil analisis SIG menunjukkan kemiringan lereng pada lokasi penelitian dengan kisaran $\geq 40 \%$ (curam) paling mendominasi dengan luasan 5.963 ha, kemiringan lereng dengan kisaran 14 - 25 
ge Ografi

$\%$ (landai - miring) dengan luas 542 ha. dan 26 - 40\% (curam) dengan luas 2.629 ha (Tabel 5). Lebih lanjut Knighton et al, (2017) menjelaskan penggunaan lahan
Available at http://jurnal.unimed.ac.id/2012/index.php/geo e-ISSN: 2549-7057 | p-ISSN: 2085-8167

kebun campuran dan lahan terbuka memberi pengaruh besar dalam meningkatkan erosi lahan.

Tabel 5. Nilai Kemiringan dan Panjang Lereng

\begin{tabular}{lcccc}
\hline Satuan Lahan & Lereng (\%) & Nilai(L/S) & Luas (ha) & (\%) \\
\hline V2.IV.QTau.And.Ht & $\geq 40$ & 11,46 & 5963 & 65 \\
V2.IV.QTau.Lat.Ht & $\geq 40$ & 10,53 & & \\
V2.III.QTt.Lat.Ht & $26-40$ & 8,15 & 2629 & 29 \\
V2.III.QTau.Lat.Sbl & $26-40$ & 9,07 & & \\
V2.II.QTau.Lat.Kc & $14-25$ & 3,26 & 542 & 6 \\
V1.II.Qal.Lat.Sw & $14-25$ & 2,68 & 9134 & 100 \\
\hline
\end{tabular}

Sumber: Ekstraksi Data DEM dan Survei Lapangan

Kemiringan dan panjang lereng adalah dua sifat topografi yang paling berpengaruh terhadap aliran permukaan dan erosi (Arsyad, 2010). Maka dari itu semakin panjang suatu lereng akan semakin banyak volume tanah yang terbawa oleh aliran permukaan dan semakin curam kemiringan lereng, maka semakin cepat pula aliran permukaan mengangkut tanah. Berdasarkan penelitian Hardjowigeno (2003) yang menyatakan bahwa erosi akan meningkat apabila lereng semakin curam atau semakin panjang.
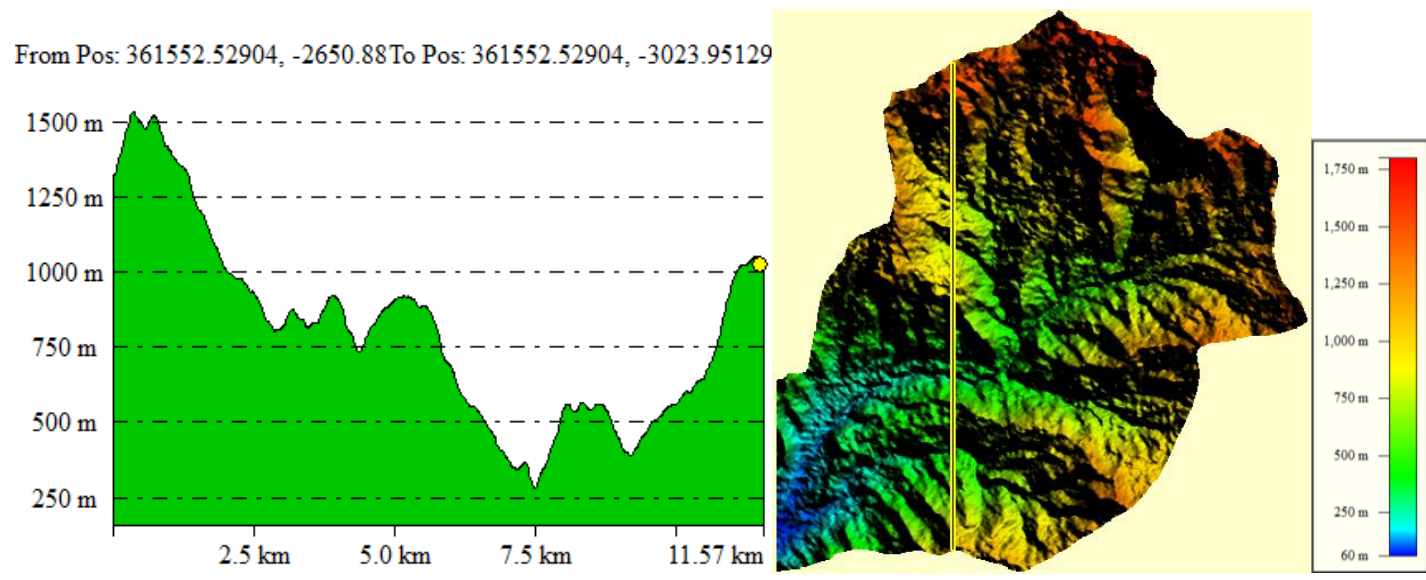

From Pos: $361414.32268,-2975.17$ To Pos: $361725.06117,-2698.75986$ $1750 \mathrm{~m} \ldots \ldots \ldots$
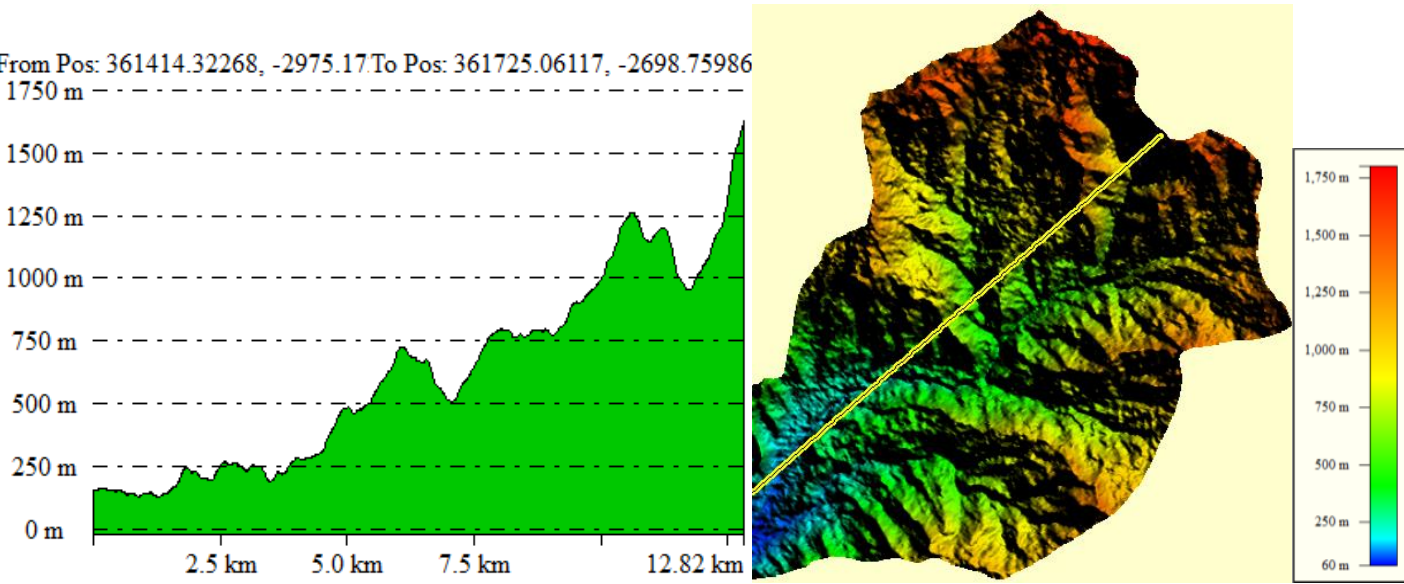

Gambar 3. Visualisasi Kondisi Kemiringan Lereng Berdasarkan Data DEM 


\section{Penutup lahan dan Arahan Konservasi (CP)}

Faktor selanjutnya yang mempengaruhi erosi dalam melindungi permukaan tanah terhadap kerusakan adalah vegetasi penutup tanah. Faktor vegetasi penutup tanah dan arahan konservasi $(\mathrm{CP})$ yang nilainya diperoleh berdasarkan jenis penggunaan lahan. Dari analisis SIG dalam menentukan sebaran jenis penggunaan lahan untuk menentukan nilai faktor CP. Maka diperoleh 4 jenis penggunaan lahan pada lokasi penelitian yaitu hutan, kebun campuran, sawah dan semak (Tabel 6).

Tabel 6. Nilai Penutup Lahan dan Arahan Konservasi

\begin{tabular}{llccc}
\hline \multicolumn{1}{c}{ Satuan Lahan } & Penggunaan lahan & $\mathbf{C}$ & $\mathbf{P}$ & Indeks CP \\
\hline V2.IV.QTau.And.Ht & Hutan & 0,001 & 0,01 & 0,00001 \\
V2.IV.QTau.Lat.Ht & Hutan & 0,001 & 0,01 & 0,00001 \\
V2.III.QTt.Lat.Ht & Hutan & 0,001 & 0,01 & 0,00001 \\
V2.III.QTau.Lat.Sbl & Semak Belukar & 0,001 & 0,20 & 0,0002 \\
V2.II.QTau.Lat.Kc & Kebun Campuran & 0,1 & 0,04 & 0,004 \\
V1.II.Qal.Lat.Sw & Sawah & 0,01 & 0,04 & 0,0004 \\
\hline
\end{tabular}

Sumber: Analisis Citra Satelit dan Survei Lapangan

Berdasarkan Tabel 6, terlihat bahwa nilai $\mathrm{CP}$ pada penggunaan lahan semak belukar, kebun campuran dan sawah memiliki nilai $\mathrm{CP}$ yang tinggi, dikarenakan tanaman yang ditanam tidak memiliki perakaran yang baik dan kuat dalam menahan curah hujan. Hal ini dapat merusak lapisan permukaan tanah apalagi ditambah dengan kondisi kemiringan lereng yang curam. Akan tetapi, berbeda dengan penggunaan lahan hutan yang memiliki nilai $\mathrm{CP}$ yang rendah, dikarenakan hutan pada lokasi penelitian mempunyai tajuk dan kerapatan yang tinggi juga perakaran yang kuat sehingga kemampuan dalam menahan curah hujan sangat besar.

Berdasarkan penelitian Bhan \& Behera (2014) vegetasi mempunyai pengaruh yang besar terhadap erosi karena vegetasi menghalangi air hujan agar tidak jatuh langsung di permukaan tanah, sehingga kekuatan untuk menghancurkan tanah dapat dikurangi. Akan tetapi, dalam pengaruh vegetasi penutup tanah tersebut perlu juga dilihat ketinggian tajuk dan kerapatan tajuk yang mempengaruhi butiran-butiran hujan yang menimpa permukaan tanah. Selain itu, perakaran tanaman sangat berperan sebagai pemantapan agregat dan memperbesar porositas tanah.

\section{Analisis Tingkat Bahaya Erosi}

Analisis tingkat bahaya erosi di lokasi penelitian diperoleh dari perkalian nilai parameter tingkat bahaya erosi yaitu erosivitas (R), erodibilitas (K), panjang/kemiringan lereng (LS), dan penutup lahan/arahan konservasi (CP). Dari nilai erosi per satuan lahan, kemudian dilakukan pengelompokkan berdasarkan tingkat bahaya erosi pada tiap satuan lahan yang bertujuan untuk mengetahui potensi erosi yang terjadi pada lokasi penelitian. Perhitungan tingkat bahaya erosi dengan membandingkan hasil prediksi erosi yang terjadi (A) menggunakan metode USLE dengan erosi yang ditoleransikan (T)(Tabel 7). 
Tabel 7. Nilai Besar Erosi dan Tingkat Bahaya Erosi

\begin{tabular}{lcccccc}
\hline Satuan Lahan & $\begin{array}{c}\text { Besar Erosi } \\
\text { (A)ton/ha/t } \\
\text { h }\end{array}$ & $\begin{array}{c}\text { Luas } \\
\text { (ha) }\end{array}$ & $\begin{array}{c}\text { Besar } \\
\text { Erosi } \\
\text { ton/ha/th }\end{array}$ & $\begin{array}{c}\text { Solum } \\
\text { Tanah } \\
\text { (cm) }\end{array}$ & & \multicolumn{2}{c}{$\begin{array}{c}\text { Tevel } \\
\text { Erosi }\end{array}$} & Kelas \\
\hline 2.IV.QTau.And.Ht & 4,73 & 485 & 22,94 & 91 & SR & 0 \\
V2.IV.QTau.Lat.Ht & 1,20 & 5376 & 64,51 & 93 & SR & 0 \\
V2.III.QTt.Lat.Ht & 1,24 & 2392 & 29,66 & 71 & $\mathrm{R}$ & $\mathrm{I}$ \\
V2.III.QTau.Lat.Sbl & 74,91 & 433 & 324,36 & 86 & $\mathrm{~B}$ & $\mathrm{III}$ \\
V2.II.QTau.Lat.Kc & 181,64 & 391 & 710,21 & 94 & $\mathrm{~S}$ & $\mathrm{II}$ \\
V1.II.Qal.Lat.Sw & 42,66 & 57 & 24,32 & 101 & $\mathrm{R}$ & $\mathrm{I}$ \\
\hline Total Luasan & \multicolumn{7}{c}{9134} & 0,57 & & & \\
\hline
\end{tabular}

Sumber: Hasil Analisis Data dan Survei Lapangan

Hasil perhitungan untuk tingkat bahaya erosi pada Tabel 7 menunjukkan bahwa dari 6 satuan lahan terdapat 1 satuan lahan dengan erosi berat, diikuti dengan 1 satuan lahan dengan erosi sedang, kemudian 2 satuan lahan dengan erosi ringan dan 2 satuan lahan dengan erosi sangat ringan (Gambar 3). Dengan didapatnya nilai tingkat bahaya erosi berdasarkan luasan keseluruhan lokasi penelitian, maka diketahui bahwa 64\% luasan lokasi dengan tingkat bahaya erosi yang sangat ringan dengan luas $5.861 \mathrm{ha}$, kemudian $27 \%$ luasan lokasi dengan tingkat bahaya erosi yang ringan dengan luas 2449 ha, diikuti 5\% luasan dengan tingkat bahaya erosi yang berat dengan luas 433 ha, dan yang terakhir 4\% luasan lokasi dengan tingkat bahaya erosi yang sedang dengan luas 391 ha.

Jika dilihat pada satuan lahan tersebut yang memiliki nilai besar erosi yang lebih kecil dibanding dengan erosi yang ditoleransi, maka lokasi ini memiliki penggunaan lahan hutan dan sawah. Sedangkan lokasi yang memiliki penggunaan lahan kebun campuran dan semak belukar dengan kemiringan lereng curam memiliki nilai besar erosi yang lebih besar dibanding dengan erosi yang ditoleransi. Rusman (1999) menyatakan bahwa vegetasi merupakan salah satu faktor penting dalam mempengaruhi besar kecil erosi disuatu tempat.

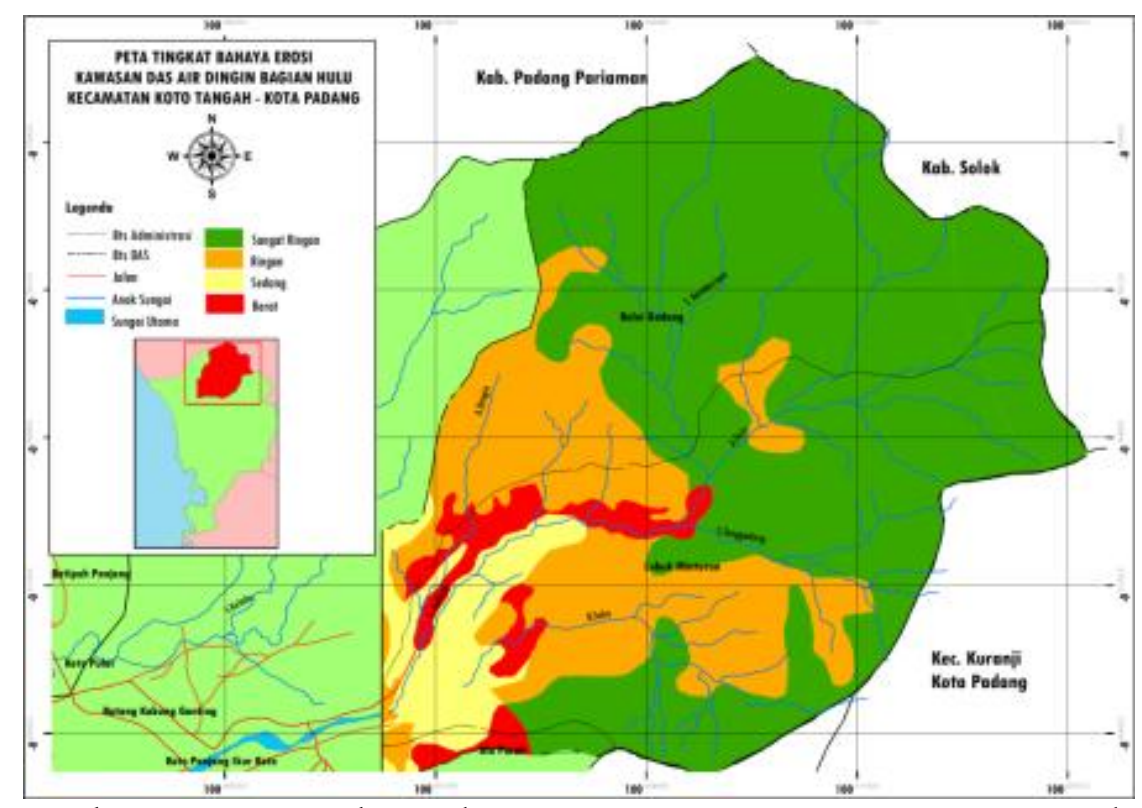

Gambar 3. Peta Tingkat Bahaya Erosi DAS Air Dingin Bagian Hulu 


\section{Analisis Arahan Konservasi}

Untuk menjaga agar kerusakan tanah tidak terjadi dan tanah dapat digunakan secara baik. Maka, nilai erosi (A) harus ditekan menjadi sama atau lebih kecil dari 30 ton/ha/th, yaitu dengan menetapkan nilai penutup lahan (C) dan arahan konservasi $(\mathrm{P})$ yang disesuaikan.

Berdasarkan nilai $\mathrm{CP}$ pada lokasi penelitian, ternyata nilai CP saat sekarang bervariasi yaitu antara 0,00001 0,004(Tabel 8), dan CP yang diperlukan antara 0,006- 0,06. Berdasarkan nilai CP yang ada pada saat sekarang dibandingkan dengan nilai $\mathrm{CP}$ yang diperlukan pada setiap satuan lahan ternyata terdapat satuan lahan yang $\mathrm{CP}$ saat sekarang $\geq \mathrm{CP}$ yang diperlukan. Untuk menekan erosi menjadi sama atau lebih dari 30 ton/ha/th harus dilakukan pengelolaan tanaman/pola tanam yang menpunyai nilai $\mathrm{CP} \leq \mathrm{CP}$ yang diperlukan.

Tabel 8. Pendugaan Arahan Konservasi

\begin{tabular}{lccc}
\hline \multicolumn{1}{c}{ Satuan Lahan } & $\begin{array}{c}\text { Besar Erosi } \\
\text { (A)ton/ha/th }\end{array}$ & Nilai CP saat sekarang & $\begin{array}{c}\text { Nilai CP } \\
\text { yangdiperlukan }\end{array}$ \\
\hline V2.IV.QTau.And.Ht & 4734,28 & 0,00001 & 0.006 \\
V2.IV.QTau.Lat.Ht & 1197,34 & 0,00001 & 0.025 \\
V2.III.QTt.Lat.Ht & 1235,26 & 0,00001 & 0.024 \\
V2.III.QTau.Lat.Sbl & 3745,35 & 0,0002 & 0,008 \\
V2.II.QTau.Lat.Kc & 454,11 & 0,004 & 0,06 \\
V1.II.Qal.Lat.Sw & 1066,51 & 0,0004 & 0,028 \\
\hline
\end{tabular}

Sumber: Hasil Analisis Data dan Survei lapangan

Bentuk tindakan konservasi pada DAS Air Dingin bagian hulu adalah dengan cara vegetatif dan mekanik. Cara vegetatif meliputi penggiliran tanaman, penghijauan dan pola tanaman tumpang sari, sedangkan cara mekanik meliputi penanaman menurut garis kontur, pembuatan teras tradisional, dan teras bangku (Suripin, 2001). Disamping masih adanya praktek pengolahan yang menyalahi aturan pada lokasi penelitian, misalnya pembabatan vegetasi penutup utama untuk area perladangan serta tanpa pembuatan teras dan saluran drainase yang tak beraturan pada lahan perkebunan, menyebabkan kinerja erosi semakin tinggi karena air hujan yang jatuh ke permukaan langsung dialirkan tanpa ada vegetasi penutup yang menahan permukaan lahan yang terbuka. Hasil analisis dari tingkat bahaya erosi dan bentuk konservasi yang diperoleh selanjutnya dilakukan upaya arahan konservasi yang mengacu pada arahan konservasi dari Kumajas (1992) (Tabel 9).

Sedangkan alternatif arahan konservasi pada penggunaan lahan hutan yaitu dengan perlakukan terhadap lahan dibiarkan dalam keadaan alami. Alternatif arahan konservasi pada penggunaan lahan semak belukar adalah pengelolaan terbatas dengan perlakukan terhadap lahan yaitu pembuatan teras bangku, penggarapan dengan tenaga manusia. Alternatif arahan konservasi pada penggunaan lahan kebun campuran dan sawah adalah pengelolaan terbatas dengan perlakukan terhadap lahan yaitu pembuatan rotasi tanaman, pemanfaatan mulsa, teras berdasarkan lebar (Gambar $3)$. 
Tabel 10.Bentuk Konservasi dan arahan konservasi

\begin{tabular}{lll}
\hline \multicolumn{1}{c}{ Satuan Lahan } & \multicolumn{1}{c}{ Pengelolaan } & \multicolumn{1}{c}{ Arahan Konservasi } \\
\hline V2.IV.QTau.And.Ht & TakTerganggu & Di biarkandalam keadaan alami. \\
V2.IV.QTau.Lat.Ht & Tak Terganggu & Di biarkan dalam keadaan alami. \\
V2.III.QTt.Lat.Ht & Tak Terganggu & Di biarkan dalam keadaan alami. \\
V2.III.QTau.Lat.Sbl & Strip Tanaman & Terasbangku,Penggarapan \\
V2.II.QTau.Lat.Kc & Teras Bangku & Rotasi tanaman, pemanfaatan mulsa, teras lebar. \\
V1.II.Qal.Lat.Sw & Teras Bangku & Rotasi tanaman, pemanfaatan mulsa, teras lebar. \\
\hline
\end{tabular}

Sumber: Modifikasi Parameter, Suripin, 2001

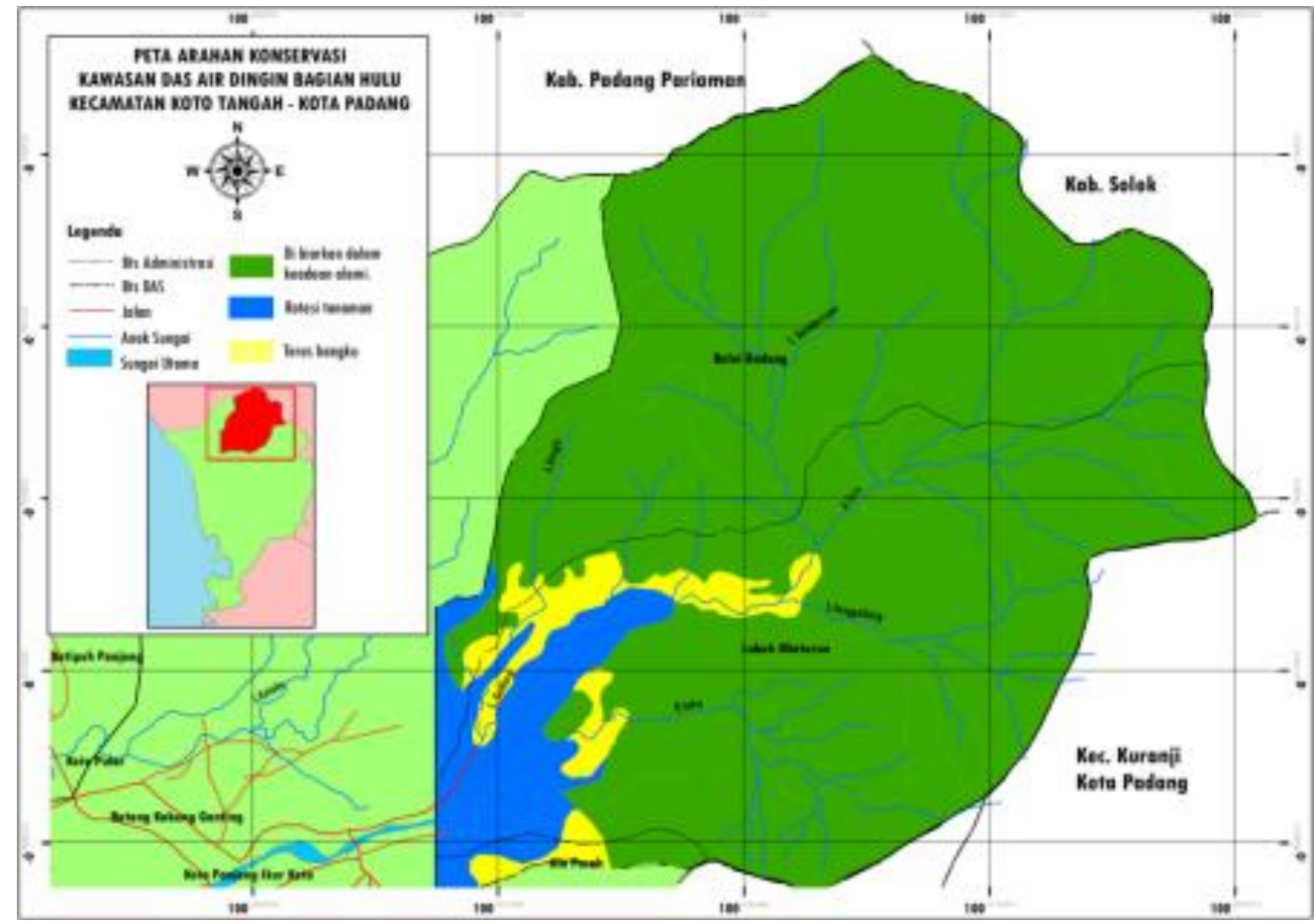

Gambar4. Peta Arahan Konservasi DAS Air Dingin Bagian Hulu

\section{KESIMPULAN}

DAS Air Dingin bagian hulu merupakan DAS yang terletak di utara Kota Padang dengan Luas DAS Air Dingin bagian hulu adalah 9.134 ha. Tingkat bahaya erosi pada DAS Air Dingin bagian hulu yaitu sangat ringan, ringan, sedang dan berat dengan nilai erosi 1,20-181,64 ton/ha/th dan arahan konservasi dilakukan berdasar tingkat bahaya erosi yaitu: a) Hutan lindung dengan arahan konservasi dibiarkan dalam keadaan alami pada penggunaan lahan hutan dengan kemiringan lereng $\geq$ $40 \%$; b) Tanaman rumput - padang penggembalaan hutan produksi atau hutan lindung/cagar alam dengan arahan konservasi teras bangku, penggarapan dengan tenaga manusiapada penggunaan lahan semak belukar dengan kemiringan lereng 26 - 40\%; dan c) Pengelolaan terbatas dengan arahan konservasi rotasi tanaman, pemanfaatan mulsa, teras berdasarkan lebar pada penggunaan lahan kebun campuran dan sawah dengan kemiringan lereng 14-25\%. DAS Air Dingin bagian hulu adalah lokasi yang rawan erosi dan longsor. Maka penduduk setempat hendaknya tidak membuka lahan baru pada hutan yang ada saat ini. Sebab, hutan yang ada saat ini memiliki fungsi hidrologis yaitu sebagai resapan air bagi lokasi di bagian bawahnya. Pemerintah setempat perlu mengarahkan masyarakat dalam pengelola lahan dengan teknik konservasi lahan seperti 
teras bangku, tanaman penutup tanah, penggiliran tanaman, pemanfaatan mulsa, pengelolaan tanaman yang baik untuk meminimalisasi bahaya erosi pada DAS bagian huludan penerapan hukuman yang tegas pada setiap tindakan yang dilakukan oleh pihak-pihak yang tidak bertanggung jawab yang merusak ekosistem lingkungan hidup pada DAS bagian hulu,sesuai dengan peraturan UU No.23 Tahun 1997 tentang Lingkungan Hidup.

\section{DAFTAR PUSTAKA}

Arsyad, S. (1989). Konservasi Tanah dan Air.Bogor. IPB Press.

Arsyad, S. (2010). Konservasi Tanah dan Air. Bogor. IPB Inpres edisi kedua.

Abidin, R.Z., Sulaiman, M.S \& Yusoff, N. (2017). Erosion risk assessment: A case study of the Langat River bank in Malaysia. International Soil and Water Conservation Research, 5(1), pp. 26-35.

Badan Pusat Statistik (BPS).(2013). Kota Padang Dalam Angka 2013. BPS. Padang.

Badan Pusat Statistik (BPS).(2016). Kota Padang Dalam Angka 2016. BPS. Padang.

Bhan, S \& Behera, U.K. (2014). Conservation agriculture in IndiaProblems, prospects and policy issues. International Soil and Water Conservation Research, 2(4), pp. 1-12.

Bols, P (1978). The Iso-erodent Map of Java and Madura. Belgian Technical Assistance Project ATA 105, Soil Research Institute, Bogor.

Ganasri, B.P \& Ramesh, H. (2016). Assessment of soil erosion by RUSLE model using remote sensing andGIS A case study of Nethravathi Basin. Geoscience Frontiers, 7, pp. 965-961.

Hardjowigeno, S. (2003). Ilmu Tanah Ultisol. Edisi Baru. Akademika Pressindo, Jakarta.

Hastuti, D. (2004). Evaluasi penggunaan lahan untuk arahan konservasi di daerah aliran sungai Serang Kulon
Progo Yogyakarta. [Tesis] Magister Ilmu Kehutanan (Konservasi Sumber Daya Alam) Universitas Gadjah Mada.

Hermon, D. (2012). Mitigasi Bencana Hidrometeorologi: Banjir, Longsor, Ekologi, Degradasi Lahan, Puting Beliung, Kekeringan (pp. 1-266). UNP Press.

Julien, P.Y. (2010). Erosion and Sedimentation. 2nd Edition. Published in the United States of America by Cambridge University Press, New York.

Kementerian Kehutanan (KEMHUT). (2009). Tata Cara Penyusunan Rencana Teknik Rehabilitasi Hutan dan Lahan Daerah Aliran Sungai (RTkRHL - DAS). BPDAS Agam Kuantan.

Knighton, J., Pluer, E.M., Prestigiacomo, R.A., Effler,S.W., \& M.T. Walter (2014). Topographic wetness guided dairy manure applications to reducestream nutrient loads in Central New York, USA. Journal of Hydrology: Regional Studies, 14, pp.67-82.

Kumajas, M. (1992). Kajian Morfokonservasi Daerah Tangkapan Hujan Danau Tondano. [Tesis] Yogyakarta. Sekolah Pascasarjana Universitas Gadjah Mada.

Luliro, N.D., Tenywa, J.S \& Majaliwa, J.G.M. (2016). Adaptation of RUSLE to Model Erosion Risk in a Watershed with Terrain Heterogeneity. International Journal of Advanced Earth Science and Engineering, 2(1), pp. 93107, Article ID Sci-140

Morgan, R.P.C \& Rickson, R.J. (2005). Slope Stabilization and Erosion Control: A Bioengineering Approach. Published by E \& FN Spon, an imprint of Chapman \& Hall, 2-6 Boundary Row, London SE1 $8 \mathrm{HN}$, UK. 


\section{ge Ografi}

Nearing, M.A., Xie, Y., Liu, B \& Ye, Y. (2017). Natural and anthropogenic rates of soil erosion. International Soil and Water Conservation Research. 5(2). 77-84.

Nouwakpo, S.K., Williams, C.J., AlHamdan, O.Z., Weltz, M.A., Pierson, F \& Nearing, M. (2016). A review of concentrated flow erosion processes on rangelands: Fundamental understanding and knowledge gaps. International Soil and Water Conservation Research, 4, pp. 75-86.

Peraturan Pemerintah (PP) Nomor 26 Tahun 2011 Tentang Pemindahan Pusat Pemerintahan Kota Padang dari Wilayah Kecamatan Padang Barat ke Wilayah Kecamatan Koto Tangah Kota Padang. Kementerian Sekretariat Negara RI.

Putra, A., Triyatno \& S. Husrin. (2013). Analisa Bencana Banjir di Kota Padang (Studi Kasus Intensitas Curah Hujan Kota Padang 1980 - 2009 dan Aspek Geomorfologi). Prosiding Seminar Nasional Sains dan Atmosfer. 24-33.

Rahmad, R., \& Nurman, A. (2017). Integrasi Model SWAT dan SIG dalam Upaya Menekan Laju Erosi DAD Deli, Sumatera Utara. Majalah Geografi Indonesia, 31(1), 46-55.

Ruslan, M., Fithria, A, Budi, S \& Syam'ani. (2016). A Study of Erosion Potential in Order to Rehabilitate Land and Forest in Amandit Catchment, South Kalimantan. International Journal of Forest, Soil and Erosion, 6(2), pp. 56-66.

Rusman, B. (1999). Konservasi Tanah dan Air. Fakultas Pertanian Universitas Andalas.

Rusnam, R. (2013). Analisis Spasial Besaran Tingkat Erosi pada Tiap Satuan Lahan di Sub DAS Batang Kandis. Jurnal Dampak, 10(2), pp. 149 167.

Sharma, J.B. (2008). Erosion and Sediment Modeling of The Lake Sidney Lanier Watershed. [Dissertation] Graduate Faculty of The University of Georgia.
Suripin, 2001. Pelestarian Sumber Daya Tanah dan Air. Andi Offset, Yogyakarta.

Thomas, B., Murphy, D.J \& Murray, B.G. (2016). Encyclopedia of Applied Plant Sciences. Second Edition. Academic Press is an Imprint of Elsevier.

Wang, B., Zheng, F., Römkens, M.J.M \& Darboux F. (2013). Soil erodibility for water erosion: A perspective and Chinese experiences. Geomorphology, 187, pp.1-10.

Wischmeier, W.H \& Smith, D. D. (1978). Predicting Rainfall Erosion Losses -A Guide to Conservation Planning. Washington DC. USDA Handbook No. 537.

Young, A. (1990). Agroforestry for Soil Conservation. International Council for Research in Agroforestry (ICRA). Printed in the UK by BPCC Wheatons Ltd, Exeter. 